\title{
Potential source contributions and risk assessment of PAHs in sediments from the tail-reaches of the Yellow River Estuary, China: PCA model, PMF model, and mean ERM quotient analysis
}

\author{
Chuanyuan Wang ${ }^{1,2} \cdot$ Yanmei Zou ${ }^{1,3} \cdot$ Liangju Yu ${ }^{1,2} \cdot$ Yingchun Lv $^{1,2}$
}

Received: 17 July 2019 / Accepted: 25 December 2019 / Published online: 11 January 2020

(C) Springer-Verlag GmbH Germany, part of Springer Nature 2020

\begin{abstract}
Principal component analysis (PCA), positive matrix factorization (PMF), and the mean effects range-median quotient (MERM-Q) models were employed to determine occurrence levels, sources, and potential toxicological significance of polycyclic aromatic hydrocarbons (PAHs) in surface sediments of the Yellow River Estuary, China. Due to the grain size of sediments, cumulative effects, and distribution of oil fields, the total concentration of the 16 U.S. Environmental Protection Agency (US EPA) priority PAHs (T-PAHs) measured in sediments along transects in the offshore area was $119.51 \pm 39.58 \mathrm{ng} \mathrm{g}^{-1}$ dry weight $(\mathrm{dw})$, which is notably higher than that measured in rivers $\left(75.00 \pm 12.56 \mathrm{ng} \mathrm{g}^{-1} \mathrm{dw}\right)$ and estuaries $\left(67.94 \pm 10.20 \mathrm{ng} \mathrm{g}^{-1} \mathrm{dw}\right)$. PAH levels decreased seaward along all the studied transects in coastal Bohai Bay. Multivariate statistical analyses supported that PAHs in sediments were principally derived from coal and biomass combustion, oil pollution, and vehicular emissions. Based on the MERM-Q $(0.0050 \pm 0.0017)$, PAHs were at low potential of ecotoxicological contamination level. These results provide helpful information for protecting water resources and serving sustainable development in Construction of Ecological Civilization in the Yellow River Delta.
\end{abstract}

Keywords PAHs $\cdot$ Source apportionment $\cdot$ MERM-Q $\cdot$ Risk assessment $\cdot$ Spatial distribution $\cdot$ Yellow River Estuary

\section{Introduction}

Polycyclic aromatic hydrocarbons (PAHs) have been identified by the U.S. Environmental Protection Agency (USEPA) as priority pollutants globally (Wang et al. 2017). Because they are toxic, carcinogenic, and mutagenic, PAHs have gained considerable attention from scientists, governments, and the public (Yunker et al. 2002; Machado et al. 2014; Zanardi-Lamardo et al. 2019). The harm of PAHs mainly

Responsible editor: Hongwen Sun

Chuanyuan Wang

cywang@yic.ac.cn

1 Key Laboratory of Coastal Environmental Processes and Ecological Remediation, Yantai Institute of Coastal Zone Research, Chinese Academy of Sciences, Yantai 264003, People's Republic of China

2 Center for Ocean Mega-Science, Chinese Academy of Science, Qingdao 266071, People's Republic of China

3 University of Chinese Academy of Sciences, Beijing 100049, People's Republic of China includes chemical carcinogenesis and phototoxicity. PAHcontaminated sediment may impact water quality and benthic organisms (Bandow et al., 2009). The damage of PAHs to plants is a kind of chronic injury, and the degree of injury is positively related to the concentration of PAHs (Chaineau et al. 1997). Human exposure to PAHs is mainly by inhalation of particulates carrying PAHs, dietary intake of contaminated food products, and direct contact with polluted soils (Davis et al. 2019). The source apportionment of PAHs in the environment has been well studied over the last 40 years (Davis et al. 2019). PAHs originated from pyrogenic (formed by combustion), petrogenic (derived from petroleum sources), and natural (biogenic or diagenetic) processes (Soclo et al. 2000; Stout et al. 2001; Kumar et al. 2017; Davis et al. 2019).

The Yellow River is an important source of water in China and one of the most sediment-laden rivers in the world. The Yellow River Delta (YRD) is an important oil industrial base. "Construction of High-efficiency Eco-economic Zone in the Yellow River Delta" and "Blue Economic Zone in Shandong Peninsula" have become national strategies in China (Dai et al. 2016). With the development of economy, coal combustion, industrial development, and exhaust emissions from 
ships and vehicles, PAH pollution in the Yellow River Basin is becoming more and more serious. Therefore, it is important to study the concentration, spatial distribution, and source of PAHs in aquatic sediments, especially estuarine sediments, to evaluate the impact of sediment pollution and human activities on the ecological environment health of Yellow River. Owing to their ubiquitous distribution and toxic characteristics, PAHs have been studied in Yellow River Delta in recent years (Yang et al. 2009; Yuan et al. 2014a). PAH pollution levels have been found to be moderate in the soil and sediment, and low in the surface water and groundwater of the Yellow River Estuary ( $\mathrm{Li}$ and Li 2017). The total concentrations of the 16 US EPA priority PAHs represent a very low pollution level, and in Yellow River Estuary, the petroleum combustion (Yuan et al., 2014a), biomass/coal combustion, natural gas combustion, and traffic emission are all possible sources of the PAHs (Yang et al. 2009; Yuan et al. 2014b). PAHs in water and sediments in the Cauca River, Colombia, have pyrogenic origin perhaps due to the effects of sugarcane burning during harvesting (Sarria-Villa et al., 2016).

To the best of our knowledge, detailed information on the spatial variability of PAHs distribution and potential ecotoxicological effect based on mean effects range-median quotient (MERM-Q) in sedimentary matter of Yellow River Estuary remain scarce, particularly reports covering Yellow River lower reaches, Yellow River estuary, and the adjacent offshore area in Bohai Sea. This study was designed to (i) analyze the regional differences in sediment PAHs from the Yellow River alone, the lower reaches, estuary, and its offshore area; (ii) quantitatively assess $\mathrm{PAH}$ pollution sources using principal component analysis (PCA) model; and (iii) assess potential ecotoxicological effects based on the MERM-Q. The results of this study provide valuable information on levels, sources, and potential risks of PAHs, for protecting water resources and serving the sustainable development in Construction of Ecological Civilization in the Yellow River Delta.

\section{Material and methods}

\section{Study area and sample collection}

The Yellow River is the 2nd largest river in China and the 6th largest river in the world. As the most sediment-filled big river on Earth, the Yellow River carries a huge amount of sediments to Bohai Sea every year (Yuan et al., 2014). Estuaries and coastal zones are the main areas situated between the ocean and lands. The water-sediment environment and water-salt condition of the Yellow River estuary are very complicated due to the combined influence of ocean and land hydrodynamics. Located on the YRD, Shengli Oil Field is the second biggest oil field in China. The oil exploitation activities will affect the input and deposition of organic matter in the Yellow
River (Yuan et al. 2014b). In addition, the YRD has become a major region for the development of agriculture and fisheries. Rapid economic growth in the YRD raises concerns of significant of pollution and ecological environment protection.

Surface sediments $(0-5 \mathrm{~cm})$ were collected in April 2013 from the lower reaches of Yellow River (R1-R11), Yellow River Estuary (ES1-ES4), and its offshore area of Bohai Sea $\left(\mathrm{MA}_{1-5}, \mathrm{MB}_{1-4}, \mathrm{MC}_{1-4}\right.$, and $\mathrm{MD}_{1-5}$ transects) (Fig. 1). The sediments were collected using a Van Veen style stainless steel grab sampler. The sediment sample was taken from each location three times and mixed to represent a sample from a sampling station. The weight of each sample was about 500-1000 g. The Lijin Hydrographic Station (R1) is the last hydrographic station before the Yellow River enters the Bohai Sea. R11 is the Xintan Oil Field Floating Bridge, which is regarded as the Yellow River's entrance. The sediment samples packed in aluminum foil were transported to the laboratory within $48 \mathrm{~h}$ and frozen at $-20^{\circ} \mathrm{C}$ until analysis.

\section{Sample extraction, separation, and GC-MS analysis}

The procedure used in the present study for sample extract purification and fractionation of PAHs was modified from previous studies (Yang et al. 2009; Yuan et al. 2014a; Wang et al. 2017). Briefly, freeze-dried sediments (10 g) were ground and homogenized by a mortar and pestle. After grinding, the samples were packed with clean filter (paper was extracted) and extracted by the Soxhlet method. The sediment samples were extracted using the Soxhlet apparatus with $n$ hexane/dichloromethane $(50 / 50)$ for $48 \mathrm{~h}$. The extract was concentrated to about $1 \mathrm{~mL}$ on a rotating evaporator, $10 \mathrm{~mL}$ of $n$-hexane was added, and then concentrated to $1-2 \mathrm{~mL}$ to convert the solvent. Solvent replacement concentrate was purified by adding silica gel alumina purification column. The glass chromatography column was packed with silica gel activated at $150{ }^{\circ} \mathrm{C}$ after Soxhlet extraction (100-200 mesh). The column was first eluted with $n$-hexane to remove aliphatic hydrocarbons and then with mixed dichloromethane and $n$-hexane $(1: 1, \mathrm{v} / \mathrm{v})$ for PAHs.

PAHs were determined on an Agilent 7890A gas chromatography (GC) coupled to a 5975C mass selective detector (MS) equipped with a HP-5 MS capillary column (specification, $30 \mathrm{~m} \times 0.25 \mathrm{~mm}$ i.d. $\times 0.25 \mu \mathrm{m}$ film thickness). Samples were injected in splitless mode and helium was used as the carrier gas. The injection temperature was $280{ }^{\circ} \mathrm{C}$. The column temperature was programmed to ramp from $80^{\circ} \mathrm{C}$ (held for $1 \mathrm{~min}$ ) to $280^{\circ} \mathrm{C}$ at a rate of $5{ }^{\circ} \mathrm{C} \mathrm{min}-1$, and held at $280^{\circ} \mathrm{C}$ for $12 \mathrm{~min}$. On the other hand, each target PAH was quantified based on the retention time and the $\mathrm{m} / \mathrm{z}$, ratio of an authentic PAH mixed standard (Sigma). Five surrogate standards (naphthalene-d8, phenanthrene-d10, dibenzothiophene-d10, fluoranthene-d10, and pyrene-d10) were added to all the samples to monitor the matrix effects. The quantification of each 


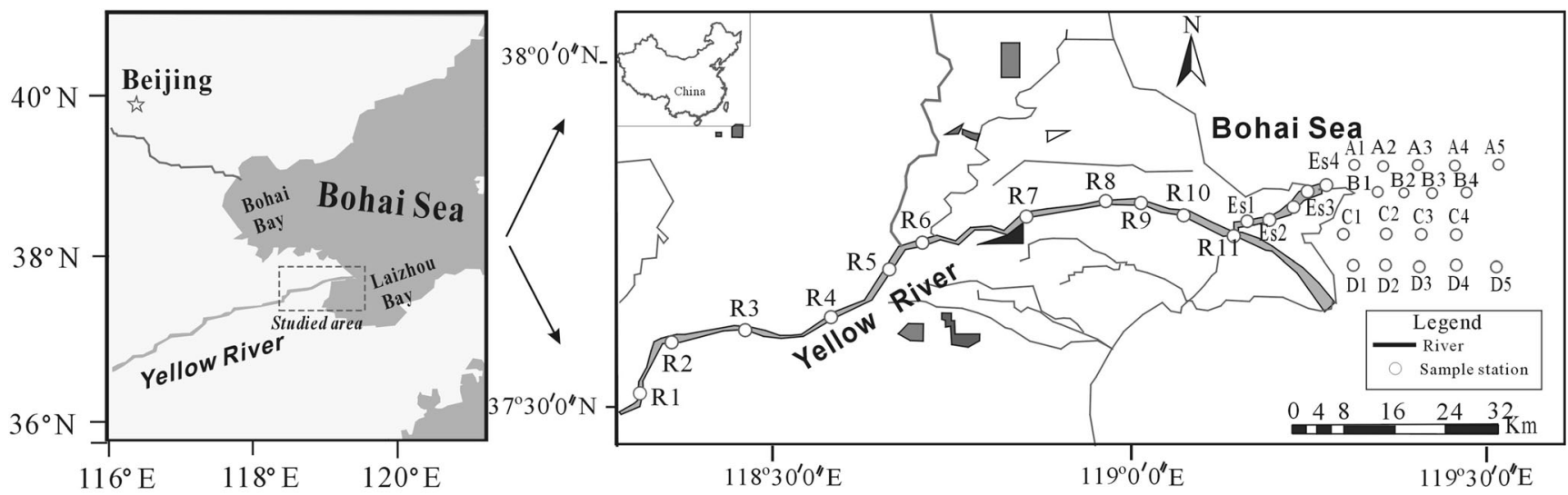

Fig. 1 Geographical map of the sites for surface sediments from tail-reaches of Yellow River Estuary. A1-A5, MA1-MA5; B1-B5, MB1-MB5; C1C5, MC1-MC5; D1-D5, MD1-MD5

individual PAH was calculated based on six-point calibration curves.

\section{Principal component analysis and PMF model}

In this paper, the source of PAHs in surface sediments from tail-reaches of Yellow River Estuary was analyzed by PCA to provide insight into the accuracy and quantification of source apportion. Data submitted for the analysis were arranged in matrix, where each column corresponds to one PAH component and each row represents sampling sites. Data matrixes were evaluated through PCA, allowing the summarized data to be further analyzed and plotted. The statistical analysis software is SPSS 13.0.

PMF is a quantitative source analysis model based on multivariate factor analysis, which was developed by Paatero and Tapper (1994) and has been widely applied to the source analysis of PAHs in aerosols, soils, and sediments (Park et al. 2015; Xu et al. 2016). In this study, EPA PMF 5.0 model was used for PAH quantitative source analysis. The basic equation is as follows:

$X=\mathrm{GF}+E$

$x_{i k}=\sum_{k=1}^{p} g_{i j} f_{g k}+e_{i k}$

where matrix $X$ in Eq. (1) is approximated based on the product of the source contribution matrix $G$ and source profile matrix $F$, which is then added to the residual matrix $E . x_{\mathrm{ik}}$ is the $k$ th compound concentration measured in the $i$ th sample, $g_{\mathrm{ij}}$ represents the contribution of the $j$ th source to the $i$ th sample, $f_{\mathrm{jk}}$ represents the mass fraction of the $k$ th compound from the $j$ th source, and $e_{\mathrm{ik}}$ is the residual. The goal of PMF is to minimize the object function $Q$, which is defined as the sum of the squared residues weighted by their respective uncertainties, based on Eq. (3).
$Q(E)=\sum_{i=1}^{n} \sum_{k=1}^{m}\left(\frac{e_{\mathrm{ik}}}{S_{\mathrm{jg}}}\right)$

where $u_{\mathrm{ig}}$ is the uncertainty in the gth species for the $i$ th sample. $Q(E)$ in this study can be written based on Eq. (4):

$S_{\mathrm{jg}}= \begin{cases}2 \times L_{\mathrm{MDL}} & \frac{\mathrm{x}_{\mathrm{ik}} \leq L_{\mathrm{MDL}}}{\sqrt{\left(\mathrm{RSD} \times x_{\mathrm{ik}}\right)^{2}+\left(L_{\mathrm{MDL}}\right)^{2}}} \\ x_{\mathrm{ik}>L_{\mathrm{MDL}}}\end{cases}$

Where RSD is the relative standard deviation of compound concentration value, and $L_{\mathrm{MDL}}$ is the detection limit of the method.

\section{Quality assurance and quality control (QA and QC)}

Procedural blanks, spiked blanks, spiked matrixes, and parallel samples were performed to control data quality. As for PAHs, the recoveries ranged from 86.36 to $108.62 \%$ for all 16 target analytes. Analysis of the blanks confirmed that there was no introduced contamination or other interference over the whole experiment. The relative standard deviation was < $5 \%$, indicating good repeatability.

\section{Results and discussion}

\section{Distribution of PAHs in surface sediments}

The variation in PAHs measured in surface sediments at the riverine, estuarine, and marine locations is shown in Fig. 2. It is clear that the total concentration of the 16 US EPA priority PAHs (T-PAHs) increased from the terminal channel diversion of the Yellow River toward the four transects (MA, MB, MC, and MD) in the marine area, which may be due to the accumulation of PAHs in the surface sediments of coastal Bohai Bay. The average T- 


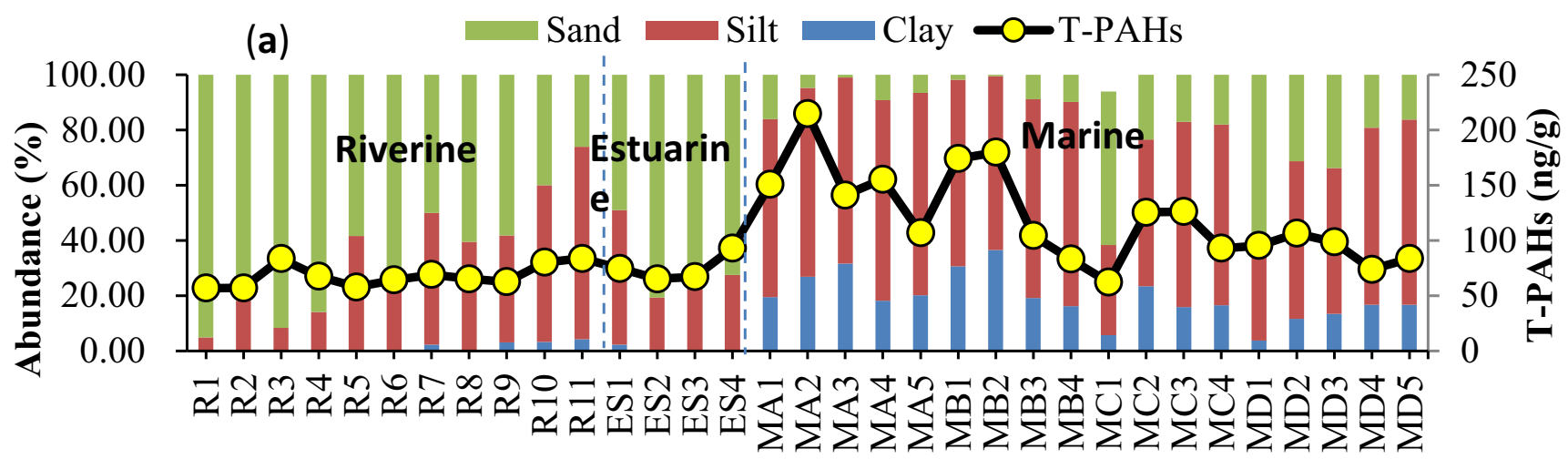

Station ID
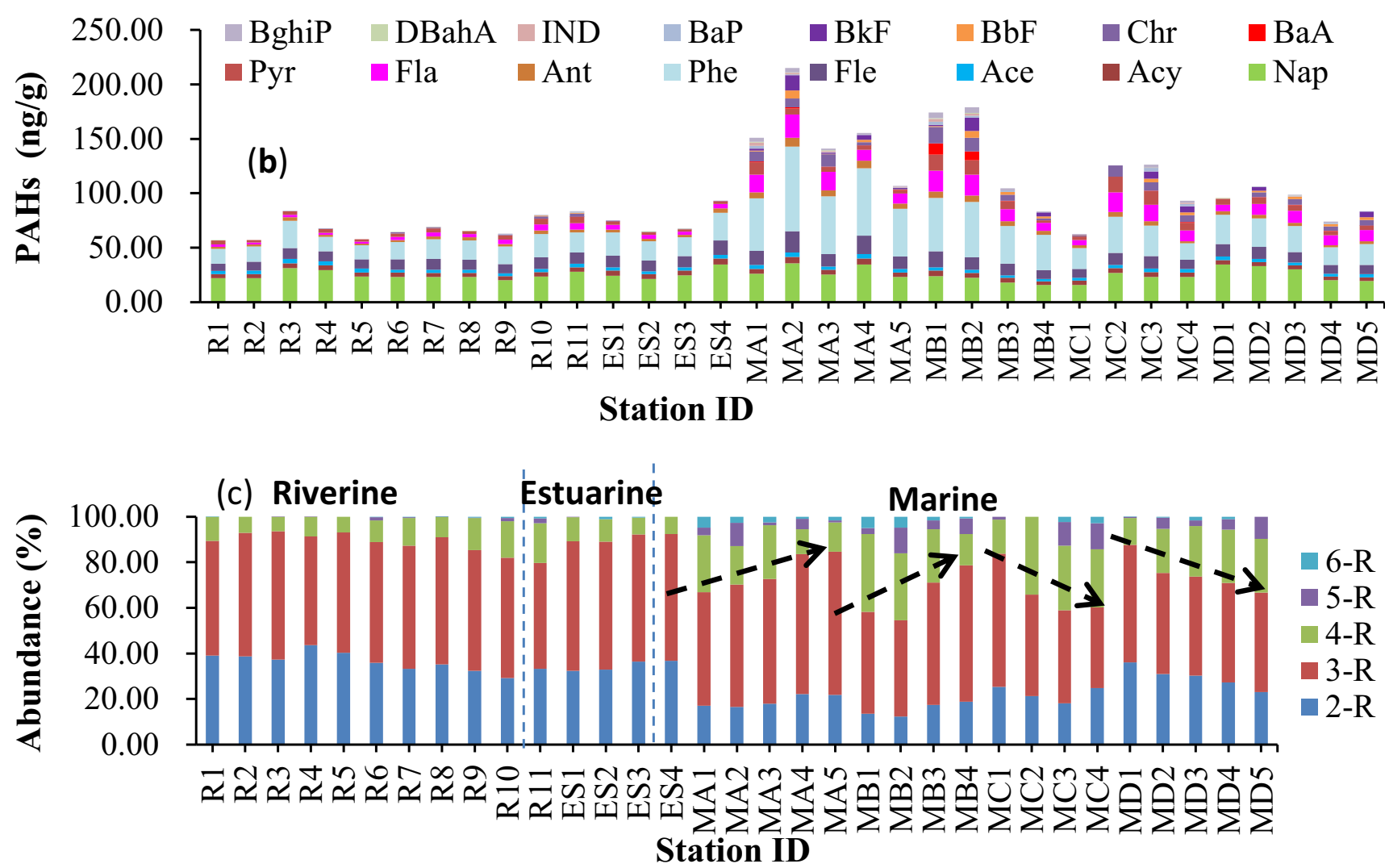

Fig. 2 Spatial variation in sediment grain size composition of sediments (a), T-PAH concentration (b), and PAH composition based on ring size in surface sediments from the tail-end of the Yellow River, the Yellow River

PAH concentration of surface sediments from the offshore area transects was $119.51 \pm 39.58 \mathrm{ng} \mathrm{g}^{-1}$ dry weight $(\mathrm{dw})$, which was higher than that measured in riverine sediments in the tail-reaches $\left(75.00 \pm 12.56 \mathrm{ng} \mathrm{g}^{-1} \mathrm{dw}\right)$ and estuarine sediments $\left(67.94 \pm 10.20 \mathrm{ng} \mathrm{g}^{-1} \mathrm{dw}\right)$. Our results are consistent with previous studies with T-PAHs of 10.8 $252 \mathrm{ng} \mathrm{g}^{-1}$ (Hui et al. 2009). In contrast, the spatial differences between river samples (downstream) and estuarine sediments are small. However, among the stations of each marine transect, stations MA1, MB1, MC1, and
Estuary, and marine transects in the Bohai Sea (c). Abbreviations for PAH compounds referred to in Table 1

MD1 had the highest T-PAH concentration (Fig. 2a). These stations occur near the river mouth and are strongly influenced by anthropogenic inputs. T-PAH concentration at stations along each transect was influenced by the distance of land-based sediment transport and settlement. Sediments mainly settle at the second station of each transect where PAHs have accumulated and the highest pollutant concentrations occur. T-PAH concentrations decreased seaward into the Bohai Sea from stations MA2, MB2, MC2, and MD2. 
The observed variation in PAHs within the estuary might be related to multiple factors such as the sediment grain size composition, PAH input rate, differential resuspension and re-deposition or vertical mixing of sedimentary PAHs, and microbial degradation of PAHs (Boonyatumanond et al. 2006). In this study, the clay component in sediments increased from land to sea (Fig. 2a). Unlike the marine sediments, sediments from the river and estuary were mainly composed of sand and silt. No significant correlation $\left(R^{2}=0.48, p \leq 0.05\right)$ was found between the median grain size (D50) and T-PAHs for studied samples. The coarse-grained sediments (silt and sand) in the river and estuary had lower levels of T-PAHs. This indicates that sediment clay content is one of the important factors restricting the accumulation and distribution of PAHs in sediments. Apart from land-source inputs from the Yellow River Estuary, oil wells and drilling platforms in the Gudong oil production area of the Shengli Oil Field in the northwest margin of the study area may also release PAHs into the sediments. Releases from the oil field may affect the composition and spatial distribution of PAHs in sediments of the Yellow River Estuary and its adjacent sea areas. As seen from Fig. 2, the concentrations of PAHs measured in the north transects $\left(\mathrm{MA}_{1-5}, \mathrm{MB}_{1-4}\right)$ were higher than those in the south transects $\left(\mathrm{MC}_{1-4}, \mathrm{MD}_{1-5}\right)$. However, dilution with seawater and the biodegradability (Brown and Maher 1992) and desorption of low molecular weight PAHs cause PAH concentrations to decrease gradually seaward into the Bohai Sea.

Naphthalene and phenanthrene were the dominant PAH compounds (Fig. 2b) with a relative average abundance of $24.9 \%$ and $27.8 \%$, respectively. Naphthalene has a low molecular weight and relatively fast decomposition rate, which indicates that there are continuous inputs of naphthalene-containing pollutants or new naphthalene entering sediments in the study area. The higher content of naphthalene in the sediments may come from frequent firewood and straw burning in the Yellow River Delta, as well as from the drilling platform of the Gudong Oil Field in the northwest part of the Yellow River Estuary.

The T-PAHs observed in the present work (56.69$214.97 \mathrm{ng} \mathrm{g}^{-1} \mathrm{dw}$ ) can be categorized as "weakly contaminated" $\left(<250 \mathrm{ng} \mathrm{g}^{-1}\right)$ (Soclo et al. 2000); they were similar to the sediment of the Pearl River Estuary, South China (59$330 \mathrm{ng} \mathrm{g}^{-1} \mathrm{dw}$; Liu et al. 2005), and Amazon River Estuary, Brazil (22.2-158 $\mathrm{ng} \mathrm{g}^{-1} \mathrm{dw}$; Rodrigues et al. 2018), but were relatively lower than those in other regions in the world, such as Mersey Estuary, UK (626-3766 $\mathrm{ng} \mathrm{g}^{-1} \mathrm{dw}$; Vane et al. 2007); Curitiba, Brazil (39-2350 ng g ${ }^{-1} \mathrm{dw}$, Machado et al. 2014); Yangtze River Estuary, China (84.6-620 $\mathrm{ng} \mathrm{g}^{-1} \mathrm{dw}$; Hui et al. 2009); and Jiaozhou Bay, China (16-2160 ng g ${ }^{-1}$ dw; Wang et al. 2006).

\section{Source apportionment}

\section{Spatial distribution patterns of PAHs}

The T-PAHs were dominated by two- to three-ring PAHs followed by four-ring PAHs and thereafter by five- to sixring PAHs (Fig. 2c). The ratio of low molecular weight PAHs (LMW PAHs, two- to three-ring) to high molecular weight PAHs (HMW PAHs, four- to six-ring) (LMW/ HMW) can be used to identify PAH sources (Tam et al. 2001). An LMW/HMW ratio > 1 indicates petrogenic source while $<1$ indicates a pyrolytic source. In the present study, the ratios were mostly $>1$, indicating that petrogenic fractions dominate the PAH accumulation in the tail-reaches of the Yellow River. Previous studies have shown that the distribution of PAH components in the Yellow River Estuary during the dry season and flood season is similar, and that naphthalene is dominant (Wang et al. 2017). This is consistent with the high naphthalene content observed in sediments in this study. The percentage of two- to three-ring PAHs in sediments of the northern transects $\left(\mathrm{MA}_{1-5}, \mathrm{MB}_{1-4}\right)$ increased gradually from the estuary toward the offshore area in the Bohai Sea. This might be because the Bohai Sea has been severely polluted by oil derived from oil exploration and exploitation activities, while the estuary is continuously scoured by water entering the sea every year resulting in relatively low oil pollution. Weakly affected by oil field exploration and exploitation, the T-PAH level in the southern transects $\left(\mathrm{MC}_{1-4}, \mathrm{MD}_{1-5}\right)$ and the percentage of two- to three-ring PAHs decreased gradually from the estuary toward the offshore area in the Bohai Sea. This might be due to the dilution of seawater and the biodegradability and desorption of low molecular weight PAHs.

\section{Source apportionment using PAH diagnostic ratios}

The source of PAHs detected in the sediment can further be determined by the molecular ratios of some PAHs. The molecular tools used to identify the sources of PAHs in sediments include ratios such as Fla/(Fla + Pyr), Ant/(Ant + Phe), BaA/ $(\mathrm{BaA}+\mathrm{Chr})$, etc. (Yunker et al. 2002). The Fla/(Fla + Pyr) ratio $<0.4$ indicates petrogenic sourcing, and values between 0.4 and 0.5 are indicative of petroleum combustion, while values $>0.5$ suggest wood, grass, and/or coal combustion (Yunker et al. 2002). An overwhelming grass, wood, and coal combustion signature was identified as a PAH pollution source of marine regions (Fig. 3a). The ratio $<0.4$ and between 0.4 and 0.5 for riverine samples provide insight to mixed sourcing of petroleum and petroleum combustion (Fig. 2). The Ant/(Ant+Phe) ratio distinguishes between petrogenic and combustion sources, as values $<0.1$ indicate petrogenic and those $>0.1$ indicate combustion (Yunker et al. 2002). It can be confirmed that PAHs in sediments mainly come from combustion process (Fig. 3a). The $\mathrm{BaA} /(\mathrm{BaA}+$ 
Fig. 3 Cross plots of diagnostic $\mathrm{PAH}$ ratios in sediment samples from tail-reaches of Yellow River Estuary
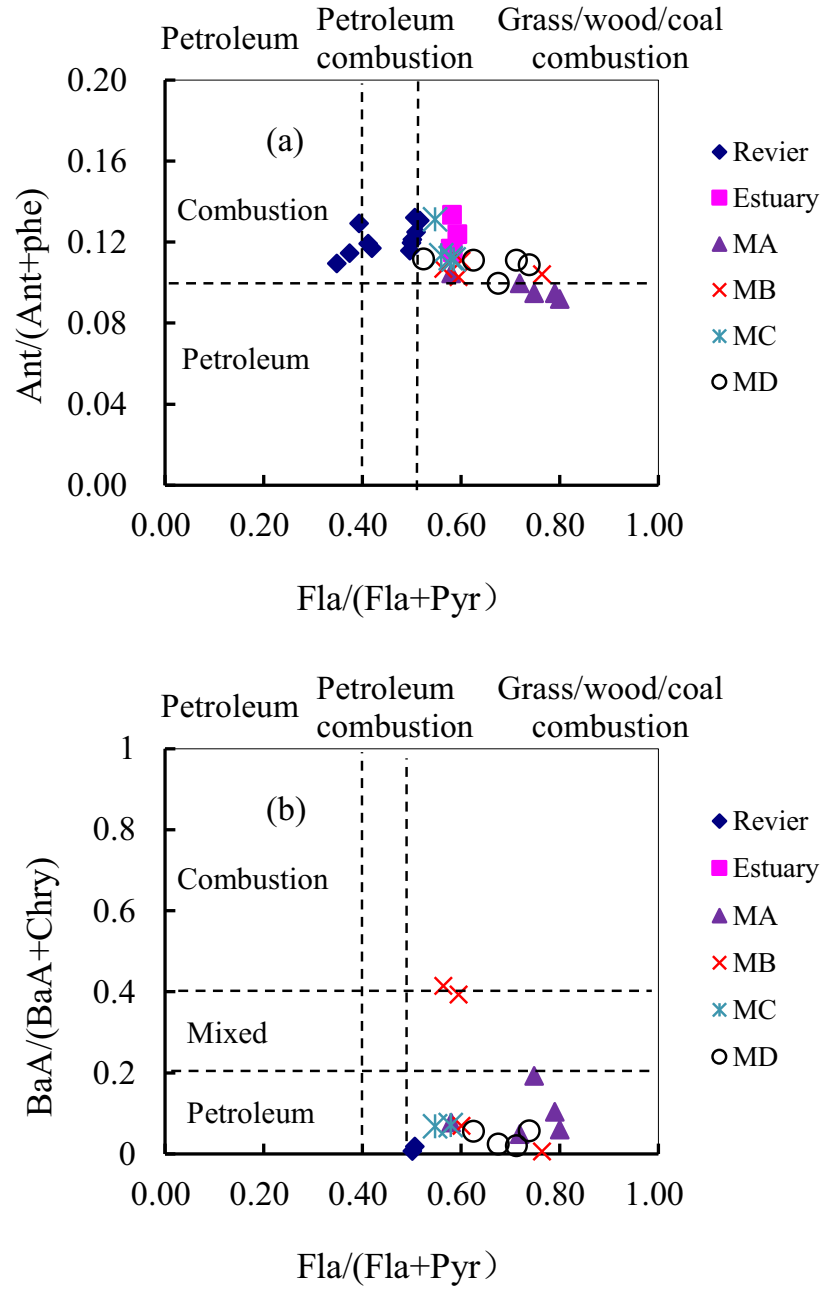

with Phe, Ant, Fla, Pyr, BaA, Chr, BkF, BaP, IcdP, and BghiP. Coal combustion emissions are enriched in Flu and Phe, and Phe and Ant can be used as markers of biomass burning (Harrison et al., 1996). In addition, $\mathrm{BaA}, \mathrm{BaP}$, and BghiP are typical markers of petroleum combustion, and oil burning emissions are enriched in Flu and Chr (Larsen and Baker 2003). Therefore, PC1 was identified as a mixed source of oil combustion, biomass burning source, and coal combustion emission. PC2 (18.11\% of the total variance) showed high loadings of Nap and Acy, which were related to sources of crude oil pollution. PC3 (6.24\% of the total variance) had high loadings on $\mathrm{BbF}$, which was reported to be the dominant tracer of incomplete diesel combustion (Venkataraman et al. 1994). For the marine area, PC1 (52.31\% of the total variance) had high loadings of PAH species including Acy, Phe, Ant, and BghiP from vehicular and coal combustion emissions. PC2 (19.36\% of the total variance) showed high a loading of Nap, which is a marker of crude oil pollution. PC3 $(9.66 \%$ of the total variance) had high loadings of $\mathrm{BbF}$ and $\mathrm{BkF}$, indicating diesel combustion. Based on PCA analysis, the 
Table 1 Factor loadings for principal components for sediment from tail-reaches of Yellow River Estuary

\begin{tabular}{|c|c|c|c|c|c|c|c|c|}
\hline \multirow[t]{2}{*}{ No. } & \multirow[t]{2}{*}{ PAH compounds } & \multirow[t]{2}{*}{ Abbreviation } & \multicolumn{3}{|c|}{ Riverine and estuarine area } & \multicolumn{3}{|c|}{ Marine area } \\
\hline & & & $\mathrm{PC} 1$ & $\mathrm{PC} 2$ & PC3 & $\mathrm{PC} 1$ & $\mathrm{PC} 2$ & PC3 \\
\hline 1 & Naphthalene & Nap & 0.23 & 0.93 & 0.15 & 0.38 & 0.66 & -0.28 \\
\hline 2 & Acenaphthylene & Acy & 0.40 & 0.86 & -0.18 & 0.83 & 0.39 & -0.13 \\
\hline 3 & Acenaphthene & Ace & 0.32 & 0.73 & 0.21 & 0.71 & 0.59 & -0.01 \\
\hline 4 & Fluorene & Flu & 0.68 & 0.58 & -0.13 & 0.79 & 0.55 & -0.18 \\
\hline 5 & Phenanthrene & Phe & 0.95 & 0.16 & -0.13 & 0.81 & 0.41 & -0.14 \\
\hline 6 & Anthracene & Ant & 0.89 & 0.29 & -0.10 & 0.86 & 0.36 & -0.13 \\
\hline 7 & Fluoranthene & Fla & 0.98 & -0.13 & 0.03 & 0.87 & -0.16 & -0.01 \\
\hline 8 & Pyrene & Pyr & 0.93 & -0.19 & 0.25 & 0.61 & -0.52 & -0.11 \\
\hline 9 & Benzo[a]anthracene & $\mathrm{BaA}$ & 0.96 & -0.17 & -0.10 & 0.63 & -0.52 & 0.02 \\
\hline 10 & Chrysene & $\mathrm{Chr}$ & 0.97 & -0.19 & 0.16 & 0.75 & -0.50 & -0.07 \\
\hline 11 & Benzo[b]fluoranthene & $\mathrm{BbF}$ & 0.61 & -0.12 & 0.69 & 0.49 & 0.19 & 0.81 \\
\hline 12 & Benzo[k]fluoranthene & $\mathrm{BkF}$ & 0.91 & -0.19 & -0.17 & 0.60 & 0.24 & 0.72 \\
\hline 13 & Benzo[a]pyrene & $\mathrm{BaP}$ & 0.97 & -0.17 & 0.13 & 0.59 & -0.54 & 0.20 \\
\hline 14 & Indeno $[1,2,3-\mathrm{c}, \mathrm{d}]$ pyrene & IcdP & 0.96 & -0.16 & -0.13 & 0.80 & -0.39 & -0.22 \\
\hline 15 & Dibenzo[a,h)anthracene & DahA & 0.74 & -0.25 & -0.47 & 0.72 & -0.32 & -0.29 \\
\hline \multirow[t]{2}{*}{16} & Benzo(g,h,i)perylene & BghiP & 0.97 & -0.19 & 0.03 & 0.90 & -0.32 & 0.14 \\
\hline & Explained variance $(\%)$ & & 66.92 & 18.11 & 6.24 & 52.31 & 19.36 & 9.66 \\
\hline
\end{tabular}

PAH contributions of the major sources for the lower reaches of the Yellow River and the estuary area were quantified as $66.92 \%$ from oil, coal, and biomass combustion; $18.11 \%$ from oil pollution; and $6.24 \%$ from diesel combustion. The PAH contributions of the major sources for the offshore area were quantified as $52.31 \%$ from oil, coal, and biomass combustion; $19.36 \%$ from oil pollution; and $9.66 \%$ from diesel combustion.
Fig. 4 Score plot of PC1 vs. PC2 illustrating the distribution of individual PAH compounds in riverine and estuarine area (a) and marine area (c); contribution ratio of pollution source of PAHs in riverine and estuarine area $(\mathbf{b})$ and marine area (d). PAH

identification numbers for clusters are given in Table 1

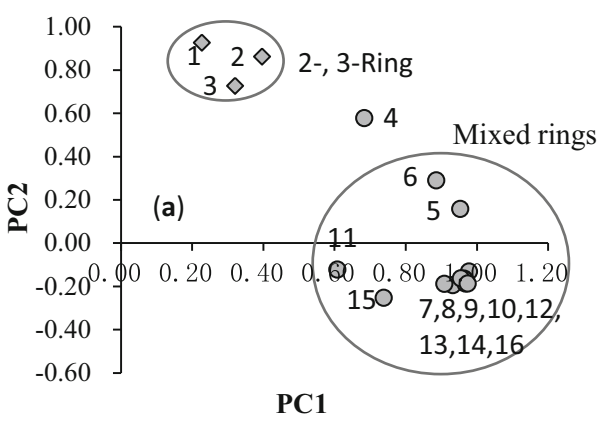

(b)

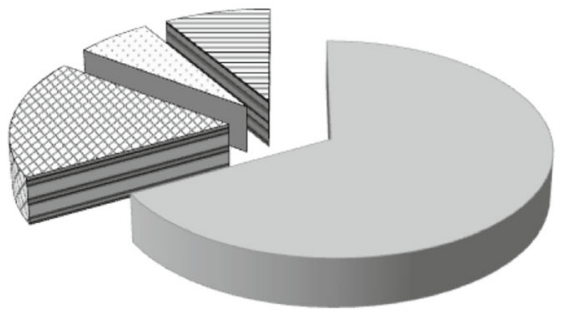

$\square$ oil, coal and biomass combustion

因 crude oil pollution

$\square$ diesel combustion

目other

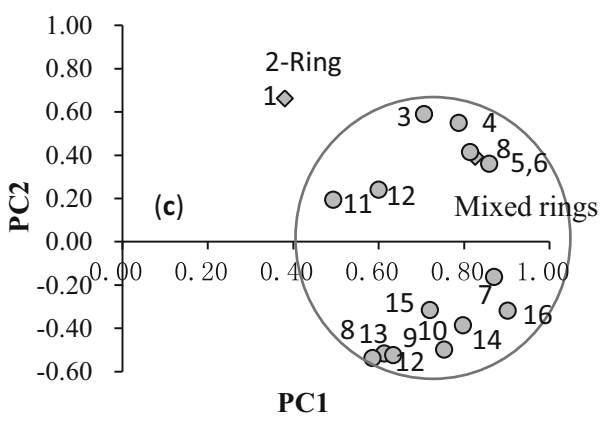

(d)
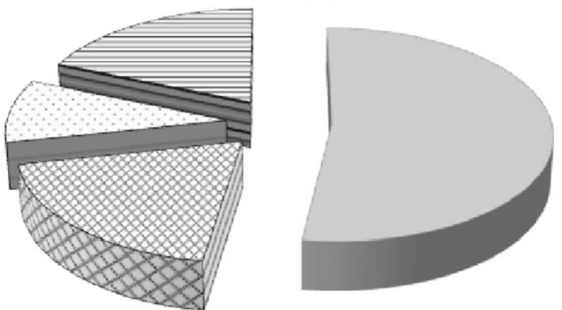

$\square$ vehicular emission and coal combustion

ø crude oil pollution

$\square$ diesel combustion

目other 
Table 2 Factor profiles of PAHs by PMF for sediment from tail-reaches of Yellow River Estuary

\begin{tabular}{llllllll}
\hline Species & \multicolumn{2}{l}{ Riverine and estuarine area } & & \multicolumn{2}{l}{ Marine area } \\
\cline { 2 - 3 } \cline { 7 - 8 } & Factor 1 & Factor 2 & Factor 3 & & Factor 1 & Factor 2 & Factor 3 \\
\hline Nap & 0.00 & 3.91 & 20.66 & 16.04 & 0.66 & 5.51 \\
Acy & 0.01 & 0.52 & 3.48 & & 2.76 & 0.02 & 0.98 \\
Ace & 0.00 & 0.47 & 2.61 & & 1.93 & 0.00 & 0.75 \\
Flu & 0.00 & 0.94 & 7.62 & & 7.18 & 0.55 & 2.45 \\
Phe & 0.19 & 1.34 & 13.82 & & 19.30 & 7.29 & 6.71 \\
Ant & 0.08 & 0.12 & 1.88 & & 2.32 & 0.71 & 0.81 \\
Fla & 0.00 & 0.00 & 1.86 & & 5.30 & 1.70 & 2.80 \\
Pyr & 0.11 & 0.34 & 2.11 & & 2.40 & 0.12 & 0.83 \\
BaA & 0.00 & 0.00 & 0.00 & & 0.03 & 0.12 & 0.03 \\
Chr & 0.12 & 0.05 & 0.03 & & 0.48 & 1.34 & 1.32 \\
BbF & 0.13 & 0.00 & 0.01 & & 0.01 & 0.09 & 1.34 \\
BkF & 0.00 & 0.00 & 0.00 & 0.02 & 0.30 & 2.87 \\
BaP & 0.00 & 0.10 & 0.00 & 0.06 & 0.00 & 0.19 \\
IcdP & 0.00 & 0.00 & 0.00 & 0.05 & 0.47 & 0.01 \\
DahA & 0.00 & 0.00 & 0.00 & 0.02 & 0.16 & 0.00 \\
BghiP & 0.06 & 0.00 & 0.00 & 0.12 & 0.41 & 0.05 \\
\hline & & & & & & \\
\hline
\end{tabular}

\section{PMF model analysis}

After inputting the sample concentration value and the uncertainty value, the factor number between 3 and 7 in turn was adjusted. The Robust mode was used for 20 times of each adjustment iteration, and the best factor number was selected according to the concentration degree of residual error between -3.0 and 3.0. $Q_{\text {Roust }}$ values (252) close to the $Q_{\text {theoretical }}$ value (265) suggest that the calculated result is reasonable. As shown in Table 2, factor 1 included relatively higher Phe, Ant, Pyr, and Chr levels in the riverine and estuarine locations, indicating coal combustion and traffic exhaust. Factor 2 was dominated by Nap and Phe, which are associated with crude oil pollution. Factor 3 had high loadings of Nap, Phe, Flu, and Fla, indicating crude oil pollution and coal combustion emission. For the marine area, factor 1 had high loadings of Nap, Phe, Flu, and Fla, which is a marker of crude oil pollution and coal combustion emission. Factor 2 was dominated by Phe, which is identified as a coal combustion emission. Factor 3 was mainly linked to coal combustion and traffic exhaust because it was enriched in Nap, Phe, Flu, Fla, and BkF.

\section{Risk assessments}

Previous studies have suggested that PAH concentrations in Yellow River Estuary, China, are below the effects range-median (ERM) and probable effects level (PEL) values (Wang et al. 2017). However, sediments often act as a sink for many pollutants where synergistic or antagonistic effects may be observed among pollutants. Therefore, the combined toxicity assessment of multiple pollutants in sediments might be higher than the toxicity of individual chemicals. The mean ERM quotient (MERM-Q) method has been used to analyze the ecological hazard of multiple toxic chemicals (McCready et al. 2006). In this paper, MERM-Q was used to evaluate the ecological risk of 15 PAHs (there is no ERM value for IcdP) in surface sediments of the lower reaches, estuary, and offshore areas of the Yellow River (Fig.5). Quotients were calculated as follows:

$\mathrm{MERM}-\mathrm{Q}=\frac{\sum\left(C_{i} / \mathrm{ERM}_{i}\right)}{n}$

where $C_{i}$ is the concentration of compound i in sediment, $\mathrm{ERM}_{i}$ is the ERM for compound $\mathrm{i}$, and $n$ is the number of compounds. The MERM-Q values can be categorized into low $(<0.1)$, medium-low $(0.11-0.5)$, medium-high $(0.51-$ 1.5), and high (>1.5) contamination (Long et al. 1995). As can be seen from Fig. 5, the MERM-Q value of all stations $(0.0050 \pm 0.0017)$ was far lower than 0.1 , suggesting that ecological risk from PAHs in the surface
Fig. 5 MERM-Q and T-PAHs in sediment from tail-reaches of Yellow River Estuary

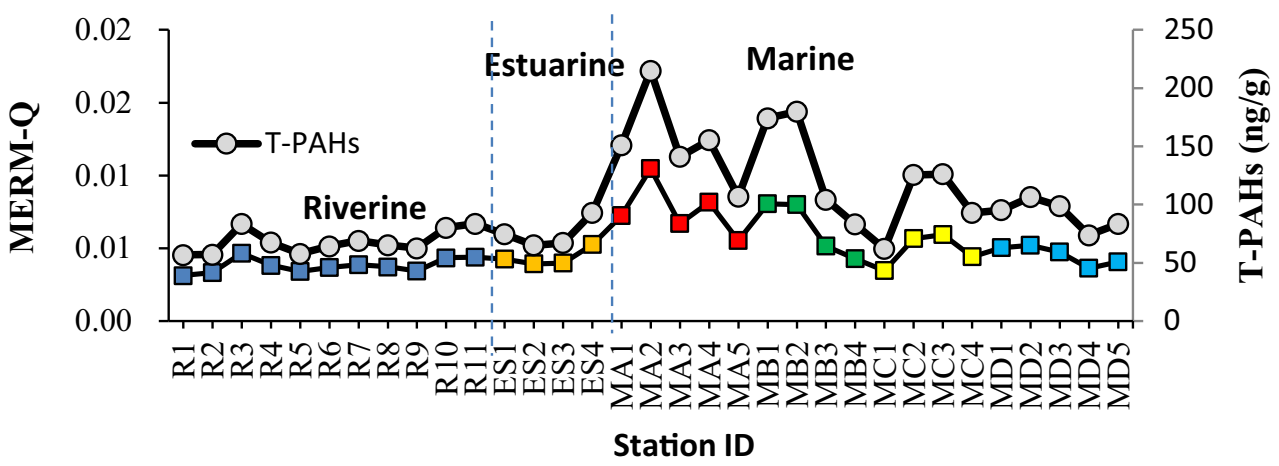


sediments of all stations is unlikely. This corresponds to the lower PAH contaminant levels in the surface sediments of the study area. Affected by oil exploitation, the risk for the northern transects in the offshore area is higher than that in the southern transects. Consistent with the concentration of aromatic hydrocarbons, the ecological risk in the offshore area is slightly higher than that in the lower reaches of the Yellow River.

\section{Conclusion}

The average concentration of 16 US EPA priority PAHs (TPAHs) in surface sediments from transects in the offshore area was $119.51 \pm 39.58 \mathrm{ng} \mathrm{g}^{-1} \mathrm{dw}$, which is higher than that measured in the riverine sediments of the lower reaches $\left(75.00 \pm 12.56 \mathrm{ng} \mathrm{g}^{-1} \mathrm{dw}\right)$ and estuarine sediments $\left(67.94 \pm 10.20 \mathrm{ng} \mathrm{g}^{-1} \mathrm{dw}\right)$. This spatial distribution may be due to the sediment grain size composition, cumulative effects, and distribution of oil fields. T-PAH concentrations in sediments generally decreased seaward along all of the studied transects in the coastal area of Bohai Bay. The percentage of two- and three-ring PAHs in sediments from the northern transects increased gradually from the estuary toward the offshore area in the Bohai Sea, possibly because the Bohai Sea is severely polluted with oil from exploration/exploitation activities, while the estuary is continuously scoured by water entering the sea every year and thus is less polluted by oil. Understanding the specific sources contributing PAHs to sediments is of importance for environmental management. Therefore, the identification of PAH sources can help assess PAH risks and control pollution in the YRD. The PAHs in surface sediments were principally derived from coal and biomass combustion, petroleum pollution, and vehicular emissions. The toxic assessment suggested that based on the PAH levels, there was low potential for ecotoxicological effects as indicated by the MERM-Q $(0.0050 \pm 0.0017)$. The ecological risk of PAHs along the northern transects was higher than that of PAHs along the southern transects, and the risk in the offshore area was slightly higher than that in the lower reaches of the Yellow River. Analyzing the ecological risk of PAHs in surface sediments from the YRD is of great significance for protecting human health and security.

Funding information This study was co-supported by Shandong Key R\&D Program (Public Welfare Project) (2019GSF109081); Key Projects in the Yantai Science \& Technology Pillar Program (2018ZHGY079), Science and Technology Service Network Initiative, Chinese Academy of Sciences (KFJ-EW-STS-127); the National Nature Science Foundation of China (No. 41971128); and the Award Program for Min River Scholar in Fujian Province (No. Min[2015]31).

\section{References}

Bandow N, Altenburger R, Streck G, Brack W, (2009) Effect-Directed Analysis of Contaminated Sediments with Partition-Based Dosing Using Green Algae Cell Multiplication Inhibition. Environ. Sci. Technol. 43:7343-7349

Boonyatumanond R, Wattayakorn G, Togo A, Takada H (2006) Distribution and origins of polycyclic aromatic hydrocarbons (PAHs) in riverine, estuarine, and marine sediments in Thailand. Mar. Pollut. Bull. 52:942-956

Brown G, Maher W (1992) The occurrence, distribution and sources of polycylic aromatic hydrocarbons in the sediments of the Georges River estuary, Australia. Org. Geochem. 18:657-668

Chaineau CH, Morel JL, Oudot J (1997) Phytotoxicity and plant uptake of fuel oil hydrocarbons. J. Environ. Qual. 26:1478-1483

Dai L, Li WJ, Zhao CZ, Zhai TT (2016) Evaluation of industrial competitiveness in the Yellow River Delta High Efficiency Eco Economic Zone based on the principal component analysis. Ecological Economy 32:127-131

Davis E, Walker TR, Adams M, Willis R, Norris GA, Henry RC (2019) Source apportionment of polycyclic aromatic hydrocarbons (PAHs) in small craft harbor $(\mathrm{SCH})$ surficial sediments in Nova Scotia. Canada. Sci. Total Environ. 691:528-537

Harrison RM, Smith DJT, Luhana L (1996) Source Apportionment of Atmospheric Polycyclic Aromatic Hydrocarbons Collected from an Urban Location in Birmingham, U.K.. Environ. Sci. Technol. 30:825-832

Hui YM, Zheng MH, Liu ZT, Gao LR (2009) Distribution of polycyclic aromatic hydrocarbons in sediments from Yellow River Estuary and Yangtze River Estuary, China. J. Environ. Sci. 21:1625-1631

Kumar A, Schimmelmann A, Sauer PE, Brassell SC (2017) Distribution and sources of polycyclic aromatic hydrocarbons (PAHs) in laminated Santa Barbara Basin sediments. Org. Geochem. 113:303-314

Larsen RK, Baker JE (2003) Source apportionment of polycyclic aromatic hydrocarbons in the urban atmosphere: a comparison of three methods. Environ. Sci. Technol. 37:1873-1881

Li J, Li FD (2017) Polycyclic aromatic hydrocarbons in the Yellow River estuary: levels, sources and toxic potency assessment. Mar. Pollut. Bull. 116:479-487

Liu GQ, Zhang G, Li XD, Li J, Peng XZ (2005) Sediment record of polycyclic aromatic hydrocarbons in a sediment core from the Pearl River Estuary, South China. Mar. Pollut. Bull. 51:912-921

Long ER, MacDonald DD, Smith SI, Calder FD (1995) Incidence of adverse biological effects within ranges of chemical concentrations in marine and estuarine sediments. Environ. Manag. 19:18-97

Machado KS, Figueira RCL, Côcco LC, Froehner S, Fernandes CVS, Ferreira PAL (2014) Sedimentary record of PAHs in the Barigui River and its relation to the socioeconomic development of Curitiba, Brazil. Sci. Total Environ. 482-483:42-52

McCready S, Birch GF, Long ER (2006) Predictive abilities of numerical sediment quality guidelines in Sydney Harbour, Australia, and vicinity. Environ. Int. 32:638-649

Paatero P, Tapper U (1994) Positive matrix factorisation: a non-negative factor model with optimal utilisation of error estimates of data values. Environmetrics 5:111-126

Park S, Cho SY, Baeb MS (2015) Source identification of water-soluble organic aerosols at a roadway site using a positive matrix factorization analysis. Sci. Total Environ. 533:410-421

Rodrigues CCDS, Santos LGGV, Santos E, Damasceno FC, Corrêa JAM (2018) Polycyclic aromatic hydrocarbons in sediments of the Amazon River Estuary (Amapá, Northern Brazil): distribution, sources and potential ecological risk. Mar. Pollut. Bull. 135:769775

Sarria-Villa R, Ocampo-Duque W, Páez M, Schuhmacher M, (2016) Presence of PAHs in water and sediments of the Colombian Cauca 
River during heavy rain episodes, and implications for risk assessment. Science of The Total Environment 540:455-465

Soclo HH, Garrigues PH, Ewald M (2000) Origin of polycyclic aromatic hydrocarbons (PAHs) in coastal marine sediments: case studies in Cotonou (Benin) and Aquitaine (France) áreas. Mar. Pollut. Bull. 40:387-393

Stout SA, Uhler AD, Boehm PD (2001) Recognition of and allocation among multiple sources of PAH in urban sediments. Environ. Claims J. 13:141-158

Tam NF, Ke L, Wang XH, Wong YS (2001) Contamination of polycyclic aromatic hydrocarbons in surface sediments of mangrove swamps. Environ. Pollut. 114:255-263

Vane CH, Harrison I, Kim AW (2007) Polycyclic aromatic hydrocarbons (PAHs) and polychlorinated biphenyls (PCBs) in sediments from the Mersey Estuary, UK. Sci. Total Environ. 374:112-126

Venkataraman C, Lyons JM, Friedlander SK (1994) Size distributions of polycyclic aromatic hydrocarbons and elemental carbon. 1. Sampling, measurement methods, and source characterization. Environ. Sci. Technol. 28:555-562

Wang XC, Sun S, Ma HQ, Liu Y (2006) Sources and distribution of aliphatic and polyaromatic hydrocarbons in sediments of Jiaozhou Bay, Qingdao, China. Mar. Pollut. Bull. 52:129-138

Wang M, Wang CY, Li YW (2017) Petroleum hydrocarbons in a watersediment system from Yellow River estuary and adjacent coastal area, China: distribution pattern, risk assessment and sources. Mar. Pollut. Bull. 122:139-148

Xu J, Peng X, Guo CS, Xu J, Lin HX, Shi GL, Lv JP, Zhang Y, Feng YC, Tysklind M (2016) Sediment PAH source apportionment in the
Liaohe River using the ME2 approach: a comparison to the PMF model. Sci. Total Environ. 553:164-171

Yang Z, Wang L, Niu J, Wang J, Shen Z (2009) Pollution assessment and source identifications of polycyclic aromatic hydrocarbons in sediments of the Yellow River Delta, a newly born wetland in China. Environ. Monit. Assess. 158:561-571

Yuan H, Li T, Ding X, Zhao G, Ye S (2014a) Distribution, sources and potential toxicological significance of polycyclic aromatic hydrocarbons (PAHs) in surface soils of the Yellow River Delta, China. Mar. Pollut. Bull. 83:258-264

Yuan ZJ, Liu GJ, Wang RW, Da CN (2014b) Polycyclic aromatic hydrocarbons in sediments from the Old Yellow River Estuary, China: occurrence, sources, characterization and correlation with the relocation history of the Yellow River. Ecotox. Environ. Safe 109:169176

Yunker MB, Macdonald RW, Vingarzan R, Mitchell RH, Goyette D, Sylvestre S (2002) PAHs in the Fraser River basin: a critical appraisal of PAH ratios as indicators of PAH source and composition. Org. Geochem. 33:489-515

Zanardi-Lamardo E, Mitra S, Vieira-Campos AV, Cabral CB, Yogui GT, Sarkar SK, Biswas JK, Godhantaraman N (2019) Distribution and sources of organic contaminants in surface sediments of Hooghly river estuary and Sundarban mangrove, eastern coast of India. Mar. Pollut. Bull. 146:39-49

Publisher's note Springer Nature remains neutral with regard to jurisdictional claims in published maps and institutional affiliations. 